\title{
JOHN CONSTANTINE E A QUESTÃO HOMOAFETIVA: UMA ANÁLISE SOBRE REPRESENTAÇÕES LGBTI+ EM QUADRINHOS DE SUPER-HERÓIS E ANIMAÇÕES
}

\author{
JOHN CONSTANTINE Y LA PREGUNTA HOMOAFFECTIVE: UN ANALISIS DE LAS \\ REPRESENTACIONES LGBTI+ EN CÓMICS DE SUPERHÉROES Y ANIMACIONES
}
JOHN CONSTANTINE AND THE HOMOAFFECTIVE QUESTION: AN ANALYSIS OF LGBTI+ REPRESENTATIONS IN SUPERHERO COMICS AND ANIMATIONS

Mário Jorge de PAIVA ${ }^{1}$

RESUMO: O presente artigo é uma análise das representações LGBTI+ em revistas de superheróis e animações. Abordaremos mais a personagem da DC Comics John Constantine, bissexual, por ele ser um herói de uma grande editora, aparecendo junto ao Batman, Superman etc. Nossa metodologia é qualitativa, se pautando em uma análise inicial do campo de estudos e na sequência em uma análise mais aprofundada da própria personagem Constantine. Possuímos um aporte teórico que envolve, entre outros autores: Michel Foucault, Sarane Alexandrian e Dandara Cruz. Nossas conclusões envolvem ver como realmente houve uma mudança profunda ao longo do tempo, do fim do século XX ao começo do século XXI. Se antes esse tipo de questão não podia ser tão abordada, ou não podia ser abordada explicitamente, hoje há uma abertura maior para representações de personagens LGBTI+.

PALAVRAS-CHAVE: LGBTI+. Quadrinhos. Animações. John Constantine. Hellblazer.

RESUMEN: Este artículo es un análisis de representaciones LGBTI + en cómics, superhéroes y animaciones infantiles. Especialmente, nos acercaremos al personaje de DC Comics John Constantine, bisexual, porque es un héroe de una editorial importante, que aparece junto a Batman, Superman, etc. Nuestra metodología es cualitativa, basada en una amplia contribución que contiene: Michel Foucault, Sarane Alexandrian, James Green, João Trevisan, Dandara Cruz entre otros. Nuestras conclusiones implican ver cómo realmente ha habido un cambio profundo a lo largo del tiempo, desde finales del siglo XX hasta principios del siglo XXI. Si antes este tipo de pregunta no se podía abordar tanto, o no se podía abordar explícitamente, hoy hay una mayor apertura para las representaciones de caracteres LGBTI + .

PALABRAS CLAVE: LGBTI+. Historietas. Animaciones. John Constantine. Hellblazer.

ABSTRACT: This article is an analysis of $L G B T I+$ representations in comic books, superheroes, and children's animations. In particular, we will approach the character of DC Comics John Constantine, bisexual, because he is a hero of a major publisher, appearing

${ }^{1}$ Pontifícia Universidade Católica do Rio de Janeiro (PUC-RIO), Rio de Janeiro - RJ - Brasil. Doutorando no Programa de Pós-Graduação em Ciências Sociais. ORCID: https://orcid.org/0000-0001-7158-4371. E-mail: mariojpaiva91@gmail.com 
alongside Batman, Superman etc. Our methodology is qualitative, based on a broad contribution containing: Michel Foucault, Sarane Alexandrian, James Green, João Trevisan, Dandara Cruz among others. Our conclusions involve seeing how there has really been a profound change over time. If before this type of question could not be addressed as much, or could not be addressed explicitly, today there is a greater opening for representations of $L G B T I+$ characters.

KEYWORDS: LGBTI+. Comics. Animations. John Constantine. Hellblazer.

\section{Introdução}

Como é conhecido, há representações do universo amoroso não heterossexual desde tempos clássicos. Se nos utilizarmos de Sarane Alexandrian (1993), podemos ver como entre os antigos gregos e romanos haviam expressões de suas sexualidades desde Autokylos (ALEXANDRIAN, 1993, p. 13), passando pela poetisa Safo da ilha de Lesbos (ALEXANDRIAN, 1993. p. 279), até chegarmos ao Satyricon (ALEXANDRIAN, 1993, p. 23; PETRONIAN, 1981), as Sátiras de Juvenaletc. (ALEXANDRIAN, 1993, p. 28).

Como elementos culturais, as formas de representação das relações amorosas não eram totalmente livres, sendo correlacionadas aos elementos da sociedade/cultura, envolvendo disputas, questões históricas e regras. Algo que o próprio Alexandrian (1993, p. 19) trata, ao abordar os códigos de conduta e honra nas relações entre o erastes e o_eromenos ${ }^{2}$. E como se esse código não fosse seguido, haviam zombarias com termos ofensivos, vide cinedes ou katapygones, termos que seriam correlatos ao que hoje se usa quando alguém é chamado de viado, bicha etc. ${ }^{3}$.

Partindo então dessa base, de que nossas representações culturais não são neutras e estão atreladas aos elementos sociológicos e históricos, o presente artigo faz uma análise da cultura pop atual. E nos referimos as representações LGBTI+ existentes em quadrinhos e animações, nosso personagem chave será John Constantine da DC Comics.

O presente artigo se divide em cinco partes. Começou com a presente Introdução. Passa então para um segundo seguimento, chamado de Representações LGBTI+ e a questão das histórias em quadrinhos, em que abordamos como há perseguições históricas contra a comunidade LGBTI+, sendo o século XX um momento de profundas mudanças. O terceiro seguimento, John Constantine e a bissexualidade, apresenta melhor quem é tal personagem e

${ }^{2} \mathrm{O}$ primeiro termo, erastes, se refere a um homem adulto que está se relacionando com um adolescente, no caso o eromenos.

3 Uma questão que Michel Foucault (2010), por sua vez, aprofundou melhor. Mesmo que também trate das zombarias que existiam sobre os relacionamentos entre dois homens feitos (FOUCAULT, 2010, p. 245). 
como sua bissexualidade foi explorada nos gibis. A quarta parte, Representação LGBTI+ em animações, especifica um pouco de como foi a representação de John em Justice league dark e trata sobre os modos como as questões $\operatorname{LGBTI}+{ }^{4}$ estão sendo abordadas em animações. O artigo fecha com a Conclusão.

Por que tratar de quadrinhos, animações, enfim da cultura pop? Pois como mostra, por exemplo, Slavoj Žižek (2017; 2018): há formas de legitimação simbólica, ideológica, indo desde os filmes que vemos até as músicas que ouvimos.

Os desenhos animados, quadrinhos etc., são parte da cultura. E é isso que o presente artigo almeja: ver então se podemos, através de certos exemplos, perceber as alterações de como são encaradas as questões da comunidade LGBTI+. Houve mudança, por exemplo, dos anos 80 até agora?

Nossa análise é qualitativa, há em primeiro momento uma abordagem mais geral da questão e nos pautamos, mormente, em Dandara Cruz. Para na sequência analisarmos outro aporte acadêmico, que se debruçou mais sobre a personagem Constantine.

Para entendermos Constantine, também lemos algumas histórias da personagem, além de assistirmos o longa animado Justice League Dark e seu filme, Constantine de 2005. O filme não será abordado, pois tal obra pouco nos diz sobre a sexualidade da personagem, sendo uma representação pouco fiel. Também vale ressaltar como o teor do artigo, em mais de um momento, será mais descritivo e isto ocorre por tal texto possuir um intuito introdutório ao tema. Já que esse tipo de discussão sobre quadrinhos, ainda não foi muito apropriada pela academia brasileira, aparentemente.

Por que nos fiarmos mais na personagem John Constantine? Pois além de ser um produto existente em várias mídias, tendo sido apresentado nos quadrinhos, nos cinemas, na TV e em animações, demostrando sua relevância junto aos consumidores, uma cena no longa animado Justice League Dark: Apokolips war ${ }^{5}$ chamou a atenção do público, recentemente. Demostrando como a sexualidade das personagens é algo que ainda gera: curiosidades, notícias em certos portais na internet etc.

Nos referimos a uma cena, em um clube de luta clandestino, em que há um diálogo entre a personagem Raven ${ }^{6}$ e Constantine. Tudo muito breve. Constantine, surpreso, diz algo

\footnotetext{
${ }^{4}$ Sabemos que há um debate sobre o uso de tais siglas e não há um consenso final. Assim preferimos LGBTI+, que se refere a Lésbicas, Gays, Bissexuais, Travestis, Transexuais, Transgêneros e Intersexual. Havendo o + que abre espaço para o acréscimo de outras minorias.

${ }^{5}$ Longa lançado em 2020 nas plataformas digitais e em 4K, Blu-ray e DVD.

${ }^{6}$ Uma bruxa que é membro dos Teen Titans.
} 
como: it's my ex. ${ }^{7}$ Então Raven ao olhar na direção que John está observando, acha que ele está se referindo a Arlequina. ${ }^{8}$ Mas, na verdade, Constantine está falando da personagem do lado da vilã, o King Shark, ${ }^{9}$ que sorri e lhe dá uma piscadela. Constantine então coloca a mão no pescoço, envergonhado, e olha para o lado. Também sendo interessante como é um mocinho que namorou um vilão.

\section{Representações LGBTI+ e a questão das histórias em quadrinhos}

Seguindo James Green (2019), James Green e Renan Quinalha (2018), João Trevisan (2018), Adriana Nunan (2003), Bruno Bimbi (2017), Murilo Mota (2019) etc., sabemos como houve um período longo de perseguições contra minorias sexuais e até hoje problemas, vários, perduram $^{10}$.

Até o século XVIII, os homossexuais podiam ser descritos como sodomitas, em uma categoria bastante ampla, que incluía contatos sexuais entre homens, homens e animais, ou homens e mulheres de forma a desafiar a reprodução (NUNAN, 2003, p. 33). Contudo mesmo depois que as ideias religiosas não mais se mostravam como o principal filtro, para se analisar a realidade, isto não significou a aceitação simples de tais grupos. Adriana Nunan (2003, p. 30-31), seguindo a corrente foucaultiana, trata como o homossexual então começou a ser motivo de estudos, junto com, por exemplo, mulheres histéricas.

Em um quadro de avanços e retrocessos, pois se o padrão higiênico burguês colaborou para a extinção dos castigos, por exemplo, do período colonial no Brasil. Isto cobrou seu preço, na criação de um sujeito mais vigiado pelo controle terapêutico, que colocava suas referências como normas científicas. O papel do psiquiatra como também o de um aprimorador do controle sobre pessoas com práticas sexuais consideradas desviantes (TREVISAN, 2018, p. 171).

Trata Nunan (2003, p. 32) de como a psiquiatria vai progressivamente definindo a personalidade do homossexual ${ }^{11}$ como uma personalidade patológica especial. E se surgiram alguns autores favoráveis à livre expressão de tais minorias, apresentavam certas alegações

${ }^{7}$ Colocamos em inglês, pois em português a designação de gênero já iria apontar como ele estava se referindo a um homem. Afinal, traduzido, ficaria algo como: é meu ex-namorado.

${ }^{8}$ Vilã do Batman criada nos anos 90 e apresentada, originalmente, como uma namorada do vilão Coringa.

${ }^{9}$ Vilão criado nos anos 90 que, grosso modo, é um antagonista do super-herói Aquaman. Tal vilão é uma mistura de tubarão com humano, sendo uma forma híbrida.

${ }^{10}$ No Brasil, por exemplo, chocava os cristãos o pecado nefando, pois eles encaravam a sodomia como um dos quatro clamantia peccata da Teologia medieval. Sendo que tais práticas já tinham sido notadas mesmo em 1549 com o padre Manoel da Nóbrega ou em 1587 por Gabriel Soares de Souza (TREVISAN, 2018, p. 63).

11 A palavra homossexualidade propriamente dita, possivelmente, só foi criada em 1869 com o jornalista e advogado húngaro Karol Maria Kertbeny (NUNAN, 2003, p. 34). 
positivas aos olhos da época, os discursos em sua maioria eram carregados de preconceitos (NUNAN, 2003, p. 34) ${ }^{12}$.

O século XX, por sua vez, e início do século XXI, ainda se mostra momento de preconceito contra esses grupos, mas houve certos pontos de corte e avanços na liberdade sexual.

Para demonstrar como as representações dos homossexuais foram mudando, acreditamos que a literatura pode nos ajudar. Se pegarmos O bom criolo (CAMINHA, 2015) do fim do século XIX, e obras como Córidon de André Gide (GIDE, 1985) ou O beijo no asfalto de Nelson Rodrigues (RODRIGUES, 2012), ambas do século XX, vemos que a questão homossexual ainda é dramática ${ }^{13}$.

Do século XX e XXI, todavia, temos também livros como Me chame pelo seu nome, O terceiro travesseiro, One man guy, os sucessos pop de David Levithan etc., que demonstram alterações. Mesmo a autora J.K. Rowling ter relevado que um dos bruxos mais populares de sua franquia, Harry Potter, era gay, e ter uma boa aceitação do público, não se mostra algo irrelevante (NUMAN, 2003). Nos referimos aqui ao Alvo Dumbledore (GI, 2007).

Tendo em vista então que nos séculos XX e XXI as maneiras sexuais LGBTI+ foram deixando de serem consideradas doenças etc., e marcas começaram a visar, mais abertamente, o público LGBTI+ (NUMAN, 2003). Agora vejamos a questão do mercado dos quadrinhos de super-heróis americanos. Explicitamos tal questão geográfica pois sabemos, por exemplo, que no Japão há eventos diferentes acontecendo, como um forte mercado de mangás ${ }^{14}$ voltado as representações de amores homossexuais. Mas isto não será tratado no presente artigo.

Se seguirmos a análise de Dandara Cruz (2017), vamos observar como as histórias em quadrinhos de super-heróis estão relacionadas a um público mais masculino e assim representam fantasias imbuídas de características do padrão de heteronormatividade. Mas nas quatro últimas décadas, do fim do século XX ao início do século XXI, o universo LGBTI+ passou a ocupar maior espaço na pauta pública, assim passaram a apontar para algumas discussões sobre inclusão e representatividade. Nos quadrinhos de super-heróis começou a

12 “A caça aos homossexuais envolveu a polícia, juízes e a medicina, que acreditava poder detectar o homossexual por características físicas e morais, surgindo as tentativas de cura aos homossexuais, que passam por práticas como: abstinência forçada, hipnose e, no século XX, tratamentos hormonais e cirúrgicos" (NUNAN, 2003, p. 35).

${ }^{13}$ Valendo lembrar do próprio caso do autor Marquês de Sade, que chegou a passar grande parte de sua vida preso.

${ }^{14}$ Grosso modo são os quadrinhos japonês. 
existir maior visibilidade de tais grupos, algo que termina por criar embates entre leitores mais conservadores (PAIVA, 2019) ou progressistas.

Trata a autora da importância da representação para grupos minoritários (CRUZ, 2017, p. 16). E aponta os heróis como entes semidivinos, que se entranharam em nosso imaginário, com elementos de masculinidade exagerada e objetificação feminina (CRUZ, 2017, p. 18). Mas graças a certos mudanças, personagens vieram contrapor tal imagem.

A autora aponta a questão imagética e como para reafirmar a masculinidade, certos artistas clássicos muito trabalharam com os homens musculosos, algo relacionado até ao corpo das esculturas greco-romanas. É, por exemplo, o caso dos traços de Tarzan desenhados por Hal Foster, The Spirit ${ }^{15}$ ou o Flash Gordon de Alex Raymond (CRUZ, 2017, p. 43-44). E há uma desvalorização de possíveis condutas, nesses heróis, do que poderia ser visto como feminino (CRUZ, 2017, p. 43).

Algumas personagens dos anos 30, 40 e 50, do século XX, são consideradas como alusões à homossexualidade, mas as questões são ambíguas (CRUZ, 2017, p. 48). E foi de grande relevância o livro Sedução dos Inocentes de 1954. O autor, Friderick Wertham, acreditava que as histórias em quadrinhos poderiam levar os jovens não só à delinquência, mas também aos distúrbios sexuais, falando do desejo pelas mulheres das histórias e do risco da homossexualidade (CRUZ, 2017, p. 56).

Houve um período de histeria anti-quadrinhos, em 1954, afinal pais e governo ficaram preocupados (CRUZ, 2017, p. 61). Diante da ameaça de um controle estatal, as editoras criaram um próprio meio de autorregularão, o Comics Code Authority, CCA. E a obediência ao código garantia um selo na capa que tranquilizava os responsáveis pelos jovens (CRUZ, 2017, p. 61). Uma das normas envolvia a proibição de representações de perversões sexuais e falava da não representação de anormalidades sexuais (CRUZ, 2017, p. 62).

Mesmo com o CCA em vigor, começaram a surgir mais personagens com evidências de desejos anormais, nos termos dessas leituras. De qualquer forma, continuava discreto e envolvia personagens menores nas tramas (CRUZ, 2017, p. 63).

Com a liberdade sexual aflorada nos anos 60 e 70, vimos mudanças. Os comix escancararam o sexo diante desse molde conservador, mas mesmo que famosos nomes, como Robert Crumb, abordassem fetiches e orgias, a homossexualidade parecia ainda no armário (CRUZ, 2017, p. 64).

${ }^{15}$ Personagem criado por Will Eisner, em 1940. 
Com os anos 80 , ainda havia certa cortina de fumaça e se destaca a personagem do mago Extraño, da DC Comics, visto como implicitamente gay na época. Contudo seus estereótipos foram mal-recebidos, tanto por alas mais tradicionais como pelos próprios membros da comunidade gay (CRUZ, 2017, p. 66).

Como sabemos, extraño pode ser traduzido em inglês por queer e ele era extravagante, mesmo para os padrões de super-heróis. Afeminado, obcecado por seu próprio cabelo e que fazia referências a si próprio como tia. Mesmo assim, com o CCA, ele nunca se assumiu (CRUZ, 2017, p. 67). Também causando polêmica sua morte por HIV, graças a um arranhão de um inimigo (CRUZ, 2017).

A Marvel através das personagens Mística e Sina, vilãs dos X-Men, também trabalhavam com relações implícitas, as duas eram mães adotivas de outra super-heroína, a Vampira (CRUZ, 2017, p. 68).

A autora teria de tratar também de Watchmen, visto como um ponto fora da curva dos anos 80 , pelo seu tom diferente (CRUZ, 2017, p. 87) ${ }^{16}$. Fazendo essa história parte da Invasão britânica, quando autores britânicos, desiludidos com o governo Thatcher, levaram suas visões pessimistas aos quadrinhos norte-americanos (CRUZ, 2017, p. 87) ${ }^{17}$.

Em Watchmen é explicitado que a personagem secundária Silhouette era lésbica, tendo um fim trágico. Pois foi morta junto com a companheira (CRUZ, 2017, p. 88) ${ }^{18}$.

Não podemos esquecer como Neil Gaiman, com o arco A game of you de Sandman (GAIMAN, 2019), e outras produções de Alan Moore, vide V de Vingança (MOORE, 2005) viriam também a abordar mais a questão da existência de personagens LGBTI+. Todavia tais representações eram selos adultos e de linhas menos centrais dos quadrinhos.

Vale menção como a Aliança Gay e Lésbica contra a Difamação, GLAAD ${ }^{19}$, deu seu primeiro prêmio em 1992 a uma história em quadrinhos, o número 53 da publicação The Flash. Nela o ex-vilão Flautista ${ }^{20}$ se revela como gay para o Flash $(\text { CRUZ, 2017, p. 71) })^{21}$. É um momento rápido, dura poucas páginas, e não possui relação com o resto da trama, mesmo assim possui importância ao abordar o aparente desconforto inicial de Flash, que, por fim, parece ter superado o problema (CRUZ, 2017, p. 74).

\footnotetext{
${ }^{16}$ Foi publicado em 1986.

17 Tal ponto também é tratado por Carlos Assis (2016).

18 "Haviam também, na trama, suspeitas e insinuações sobre o primeiro vigilante de tal universo, o personagem secundário Justiceiro Encapuzado" (CRUZ, 2017, p. 88).

${ }^{19}$ A Gay and Lesbian Alliance against defamation é uma ONG, criada em 1985.

20 "Possuidor de poderes de superaudição e que terminou por desenvolver uma espécie de tecnologia de hipnose sonora" (CRUZ, 2017, p. 71).

${ }^{21}$ Famoso herói da $D C$ com super-velocidade.
} 
Acreditamos que valha menção, também, ao gibi Asilo Arkham, de 1989, porque presenciamos um Coringa que apresenta elementos que poderiam indicar homossexualidade ou bissexualidade.

No primeiro encontro do Batman com o vilão, ele chama o herói de docinho e chuchuzinho, perguntando também se ele não é gostoso o bastante para ser comido pelo herói. Para na sequência passar a mão no traseiro do rival, dizendo para ele relaxar. A personagem também faz menção ao Robin, pergunta se ele já se depila, dando a entender que Batman e Robin podem ser um casal. A representação do Coringa, em tal história, envolve salto alto e unhas longas e pintadas de verde.

Houve alterações no roteiro original da história, para amenizar o vilão. Na versão original, na primeira aparição do Coringa, ele estaria fazendo uma pose sedutora, como uma modelo de calendário. Estaria vestido com um collant preto, botas altas e delineadores/cílios falsos. Era um visual inspirado na Madonna, sendo citado no roteiro o videoclipe Open your heart (MORRISON, 2012).

Com o término das restrições do CCA, houve uma nova geração de artistas nos anos 90, vide Todd McFarlane ${ }^{22}$ e Rob Liefeld, para tratar de questões sexuais, mesmo que de modo apelativo (CRUZ, 2017, p. 83).

Em Gen 13, um dos produtos de 1995 da editora Image, a personagem Sarah Granizo era abertamente bissexual (CRUZ, 2017, p. 84). Mas Cruz (2017, p. 85) analisa tal personagem como um fetiche pela bissexualidade feminina, no sentido de que Granizo era quase exibicionista e adepta do nudismo. E essas representações femininas ostentavam constantemente a posição conhecida como brokeback, que busca, em termos estéticos, ressaltar as nádegas e os seios das personagens.

Dos anos 2000 em diante a autora aponta para uma representação mais positiva. Dialogando com os conflitos existentes e fazendo coro à questão da tolerância (CRUZ, 2017, p. 92). Nos Novos Vingadores, por exemplo, ganhou destaque o casal Hulkling e Wicanno, que estrearam juntos em 2005 (CRUZ, 2017, p. 93). E que, aos poucos, foram sendo apresentados como um casal para o público.

O primeiro beijo desses só viria a ser publicado em 2010 (CRUZ, 2017, p. 97). É válido relembrar como tal história, ao ser publicada no Brasil, causou polêmica com o prefeito Marcelo Crivella (MACHADO; FRANCO, 2019). Também vale relembrar o famoso beijo 
gay entre duas versões alternativas das personagens Wolverine ${ }^{23}$ e Hércules, ${ }^{24}$ na décima edição da X-Treme X-Men (CRUZ, 2017, p. 102).

A DC, por sua vez, na reformulação de suas revistas, conhecida como Novos 52, apresentou um Lanterna $\operatorname{Verde}^{25}$ homossexual. Esse em 2012 apareceu beijando seu namorado, na segunda edição de Earth 2. E o roteirista de tal história relatou, também, como muitas das reações negativas, via internet, vieram de leitores brasileiros (CRUZ, 2017, p. 99100).

O que parece incomodar mais, certa parcela dos leitores, são as relações homossexuais masculinas, como Cruz (2017) trata. Afinal, há todo um apelo em duas mulheres muito sexualizadas se beijando.

Não nos cabe fazer a genealogia de todas as representações de tais minorias em quadrinhos, mas vemos como houve uma ampliação e mudanças nas formas de representação.

Personagens bissexuais ou lésbicas foram aumentando de número: Arlequina (CRUZ, 2017, p. 105), Mulher-Gato (CRUZ, 2017, p. 108), Mulher-Maravilha etc. (CRUZ, 2017, p. 110). Assim como outros personagens masculinos foram saindo do armário, vide uma nova versão do Homem de Gelo (CRUZ, 2017, p. 113). Houve o casamento de uma personagem transgênero na publicação Batgirl (CRUZ, 2017, p. 121-122). Enfím do silêncio e das representações discretas, chegamos ao momento, no qual tais questões podem ser abordadas bastante claramente e com um aprofundamento que sai do humorístico ou do trágico.

\section{John Constantine e a bissexualidade}

Constantine apareceu primeiramente como coadjuvante em histórias do Monstro do Pântano, na época em que era escrito por Alan Moore (ASSIS, 2016, p. 36). Mas terminou ganhando um título solo. E Hellblazer se mostrou uma publicação icônica, da linha Vertigo da DC Comics ${ }^{26}$.

Hellblazer foi título lançado em 1988 e foi a publicação mais longeva do selo. Mesmo depois de seu encerramento, a personagem principal, John Constantine, passou a integrar outras histórias de tal universo editorial, apareceu em aventuras do Batman, Superman, Flash e por aí vai (ASSIS, 2016, p. 27).

${ }^{23}$ Um dos personagens mais famosos da Marvel.

${ }^{24}$ Personagem secundário da Marvel.

${ }^{25}$ Outros heróis de grande importância dentro da $D C$.

${ }^{26}$ Selo voltado para publicações mais adultas dentro de tal editora. 
Constantine rompe com o estereótipo do mago de capa, rico e/ou possuidor de posição de destaque dentro da sociedade. É um mago da classe trabalhadora (ASSIS, 2016). Evidenciando em suas histórias problemas sociais, políticos e econômicos. Em questões relacionadas à falta de liberdade de expressão das minorias sexuais, por exemplo (ASSIS, 2016, p. 31). O terror e o horror vêm de uma mistura de medo da conjuntura política/social somado aos elementos sobrenaturais (ASSIS, 2016, p. 37).

A ideia de Constantine é ser um mago das ruas, conhecedor do submundo urbano (ASSIS, 2016, p. 40). John é apresentado como vocalista e fundador de uma banda punk. Possuindo como amigos/conhecidos: Ray Monde, um homossexual soropositivo assassinado por um grupo de cristãos; Ali, comerciante paquistanês hostilizado por neonazistas; Chas, um taxista; Marj e Eddy, participantes de um movimento hippie etc. Considerando que tais histórias foram escritas na segunda reeleição de Margaret Thatcher, muitas das medidas do thatcherismo já estavam em vigor e fala o autor da Cláusula 28 , que proibia a promoção intencional da homossexualidade (ASSIS, 2016, p. 41-2) ${ }^{27}$.

É notável a forma como o escritor Jamie Delano se inspira, por exemplo, em William Burroughs para escrever Constantine, logo vemos como o elemento marginal é importante em tal construção (ASSIS, 2016). É um pária da sociedade burguesa e de seus valores (ASSIS, 2016, p. 98). Houve também influência do escritor Jack Kerouac (ASSIS, 2016, p. 99) ${ }^{28}$.

As andanças de Constantine pela cidade são um retrato de abandono. Lixo no chão, mesmo pessoas abandonadas, diante da questão da mendicância etc. (ASSIS, 2016, p. 128). Em outro momento, enquanto a narração da revista fala que há mais de um caminho que leva ao inferno, a vitória de Thatcher é anunciada na televisão, que a personagem está assistindo (ASSIS, 2016, p. 142-143). E há semelhanças entre o caso britânico e os Estados Unidos, no governo Reagan.

Constantine surgiu e se manteve muito tempo como um personagem contestador e marginal. Passando a figurar em histórias de heróis maiores, como Batman e Superman, era de se esperar mudanças. Mesmo que em algumas histórias, como Batman: Maldito, também de um selo voltado para um público mais adulto, ainda vejamos Constantine imerso em um universo sujo e decadente.

A bissexualidade da personagem não parece algo que estava presente desde sua origem. É um elemento adicionado com o escritor Brian Azzarello (SMEE, 2019). Ou seja, se

${ }^{27}$ Seção 28 ou Cláusula 28 se refere à uma medida do Local Government Act 1988, a qual só foi encerrada em 21 de Junho de 2000.

${ }^{28}$ Tratar de Kerouac é tratar da geração beat, assim Assis (2016, p. 101) os associa as camadas mais pobres e de uma estética agressiva. 
passam muitos anos entre a criação da personagem e sua declaração de bissexualidade, pois Hellblazer número 164 saiu no ano de 2001.

É no arco Inferno na Prisão, de Hellblazer, que acompanhamos sua bissexualidade. Vemos uma história, na qual Constantine está preso e se tornar a mulher de um prisioneiro mais forte. Então de um ponto inicial, de grave violência sexual, esse elemento terminou ressurgindo em outras histórias. Como no arco final de Azzarello, Cinzas e Pó na Cidade dos Anjos, no qual Constantine seduz um rico dono de uma boate sadomasoquista (SMEE, 2019). $\mathrm{Ou}$ no encadernado Fantasmas do passado, pois acompanhamos uma cena, em que Constantine vai a um bar e ao encontrar um homem que lhe atraiu, começa a flertar com o desconhecido (ARAÚJO, 2018).

\section{Representação LGBTI+ em animações}

Como é a representação de Constantine em Justice league dark: Apokolips war? Para começarmos, vale entender que os longas animados recentes da DC Comics estão a apostar em histórias mais violentas e adultas. Assim surgiu uma animação do clássico Piada mortal de Alan Moore, em que se acrescentou até uma cena de sexo entre o Batman e a Batgirl. ${ }^{29}$ Mas também é mais violento e sexual animação como Assalto ao Arkhan. Comparemos estas duas animações com Batman: A máscara do Fantasma, dos anos 90, e a diferença ficará nítida.

$\mathrm{Na}$ trama de Justice League Dark Constantine se torna um membro da Liga da Justiça ${ }^{30}$ Já inicia o longa com uma piada de que não irá colocar capa de super-herói. Mas depois de uma batalha frustrada contra o vilão Darkside, ${ }^{31}$ a terra é conquistada por dois anos pelo invasor alienígena.

Nas imagens que vemos de tal confronto, já existe um clima de maior violência, pois aparecem heróis despedaçados e mortos em tal confronto. Estelar, ${ }^{32}$ por exemplo, aparece cortada ao meio com tripas, sangue e ossos para fora. E mesmo em outras cenas a violência continua: Raven, por sua vez, em certo momento da trama ia tentar o suicídio; Batgirl é devorada viva; quebram o pescoço do Superboy, matando-o etc.

Constantine na batalha inicial, de forma nada heroica, foge do combate, deixando os outros entregues à própria sorte. A primeira vez que revemos Constantine, depois dessa

\footnotetext{
${ }^{29}$ Personagem clássica, vista, geralmente, como uma ajudante do Batman.

${ }^{30}$ Clássico grupo de super-heróis dos quadrinhos, somando Superman, Batman etc.

${ }^{31}$ Visto como um dos vilões mais poderosos da $D C$, tendo um nível de força comparável ao do Superman.

${ }^{32}$ Personagem membro dos Teen Titans.
} 
derrota, ele está bêbado, barbado e cambaleante. Em outro momento ele está fumando, algo pouco comum para os heróis atuais igualmente.

Se os heróis já foram representados como semideuses, os heróis atualmente podem aparecer em representações menos idealizadas. É o próprio caso do filme Batman v Superman ou da série The boys.

Ao receber a visita de Superman e Raven, Constantine recusa, inicialmente, o convite para salvar o mundo, acha que o plano não vai dar certo. Depois de aceitar se juntar ao grupo, acontece a cena entre ele e o King Shark. Como a revelação da homossexualidade do ex-vilão Flautista, não é algo que esteja envolvido diretamente com a trama de salvar o mundo.

Como em outros casos, não há nenhuma cena que demonstre o afeto mais profundo entre esses dois seres. Não há beijo, abraço ou qualquer coisa do gênero. Então vemos que mesmo dentro de um padrão mais adulto, as animações da DC ainda não estão investindo em demonstrações mais explícitas de homoafetividade.

Justice league dark não é caso isolado, há mais animações com personagens da comunidade LGBTI+ também. Não é nosso objetivo realizar uma lista, no presente artigo, de todas essas representações. Mas como no caso dos quadrinhos, é válido realizar um corte entre as animações com perfil mais adulto e as mais voltadas para um público bem jovem.

Assim séries animadas como South Park, já abordavam personagens homossexuais desde sua primeira temporada, com a personagem Big Gay Al, por exemplo. The Simpsons também possuiu uma personagem, Waylon Smithers, que todos já suspeitavam de sua homossexualidade, mas esse ficou no armário por muitos anos, até se revelar depois de vinte e sete temporadas do desenho. Do mesmo modo, Family Guy possui uma personagem, primo do cão falante Brian, que é assumidamente gay (UOL, 2017).

BoJack Horseman trabalhou com a trama de um personagem gay, Herb Kazzaz, que ao ser revelado ao grande público, perde seu emprego, em uma grande emissora de TV, e chega a pensar em suicídio. O programa possui igualmente um personagem assexual, Todd, um dos melhores amigos de BoJack.

Nos anos 2000 podemos detectar certos personagens de desenhos infantis que apresentaram traços que poderiam os identificar com minorias sexuais, porém como a personagem Extraño não são assumidos. Por exemplo, o vilão Ele do desenho Meninas superpoderosas, pois tal ente possui elementos femininos, como sua voz fina e a vestimenta. Outro exemplo mais pontual: em um episódio do desenho animado O laboratório de Dexter, 
do canal Cartoon Network, vemos uma paródia do Surfista prateado ${ }^{33}$. A personagem é chamada de Colher Prateada e causou polêmica por ser um gay estereotipado (UOL, 2017).

A recente novidade então parece ser representações LGBTI+ em animações voltadas mais para o público infanto-juvenil de forma aberta.

No desenho The Loud House um dos melhores amigos da personagem principal possui dois pais (VEJA, 2016). Em Avatar: A lenda de Korra, a personagem principal se apresenta, no último episódio, como bissexual, ao dar a mão a outra personagem feminina, Asami. Os autores da série vieram confirmar que se tratava de um relacionamento amoroso (UOL, 2017). Para os criadores da série terem de vir confirmar tal envolvimento, já nos explicita que foi algo discreto e dúbio. Algo similar a representação da homossexualidade de Alvo Dumbledore no filme Animais fantásticos 2.

No desenho Steven Universe duas personagens femininas, Rubi e Safira, possuem um relacionamento (UOL, 2017). Em que vale citar dois casos que trataram disto de modo mais claro: A hora da aventura e Star vs as forças do mal.

Star vs as forças do mal, da Disney, foi desenho, de maneira pioneira, a apresentar beijos gays entre personagens (G1, 2017). Em uma cena que mostra alguns casais se beijando, há, claramente, um casal de dois homens. No momento anterior, de modo menos central na imagem, também havia um casal de duas mulheres ${ }^{34}$.

No fim de A hora da aventura se dá coisa similar. As personagens Marceline e Princesa Jujuba se beijam, depois de vencerem uma ameaça juntas. Em que há uma diferença: em A hora da aventura é um casal muito importante dentro da trama, ambas queridas pelo público.

\section{Considerações finais}

O presente artigo foi sobre as representações LGBTI+ existentes em desenhos animados e quadrinhos, demos principal destaque para a personagem John Constantine, que chamou certa atenção do público e da mídia, recentemente, ao relevar um ex-namorado, em uma animação chamada Justice league dark: Apokolips war.

Como vimos na década de 80 , do século XX, já havia certas discussões sobre a sexualidade da personagem Extraño e da vilã Mística, dos X-Men, mas a representação

${ }^{33}$ Vilão clássico da Marvel, geralmente aparecendo nas histórias do Quarteto Fantástico.

${ }^{34} \mathrm{E}$ no fim da série uma das personagens principais da animação, Jackie, apareceu com uma possível namorada. 
continuava velada. Tirando histórias de quadrinhos mais adultas, como Watchmen, Sandman, $\mathrm{V}$ de vingança etc. Foi nos anos 90 que surgiu maior liberdade nos quadrinhos.

Dos anos 2000 em diante a representatividade aumentou. Aqui se pode pensar em uma série de casos: um casal gay em Novos Vingadores, um Homem de Gelo que saiu do armário, um beijo gay do Wolverine etc. No que tange ao Constantine, sua apresentação como bissexual também ocorreu no começo dos anos 2000 .

Sobre sua sexualidade apresentada na animação Justice League Dark: Apokolips war, como vimos, é algo rápido e discreto. Não há cenas de grande afeto entre a personagem Constantine e King Shark.

Sobre as animações, elas parecem, no caso americano, terem demorado mais para assimilarem a questão da representatividade LGBTI+. Mesmo assim, houve personagens gays em animações adultas, como South Park ou Family Guy.

Na década de 10, do século XXI, há representações abertas então nos desenhos. Exemplos disso são: The Loud House, Avatar, A hora da aventura, Star vs as forças do mal etc. E este último exemplo apresentou um beijo gay polêmico em um dos seus episódios. Além disso, se A hora da aventura deixou para revelar no fim da série o relacionamento lésbico de suas personagens, isso pode envolver o fato de que se houvesse alguma tentativa de boicote ao programa ou polêmica, a série já teria acabado, assim não ameaçaria tanto sua audiência, por exemplo.

A representação da comunidade LGBTI+ é variável com o tempo, envolve, entre outras coisas, o quanto a sociedade se mostra aberta ou não para as minorias sexuais.

\section{REFERÊNCIAS}

ALEXANDRIAN, S. História da literatura erótica. Rio de Janeiro: Rocco, 1993.

ANIMAIS Fantásticos: os crimes de Grindelwald. Direção: David Yates. Roteiro: J. K. Rowling. Estados Unidos e Reino Unido: Warner Brothers, 2018. 1 DVD (134 min).

ASSIS, C. H. C. Desbravando os infernos de John Constantine na revista Hellblazer (1988-1991). 2016. 181 f. Dissertação (Mestrado em História Social) - Pontifícia Universidade Católica, São Paulo, 2016.

AURÉLIO, B. Hellblazer: Constantine é bissexual. Quinta Capa, 29 nov. 2019. Disponível em: https://quintacapa.com.br/hellblazer-constantine-e-bissexual/. Acesso em: 14 jun. 2020. 
G1. Autora de Harry Potter revela que Dumbledore é gay. 20 de out. de 2007. Disponível em: http://g1.globo.com/Noticias/PopArte/0,,MUL153485-7084,00AUTORA+DE+HARRY+POTTER+REVELA+QUE+DUMBLEDORE+E+GAY.html. Acesso em: 14 jun. 2020.

BATMAN vs Superman: Dawn of Justice. Direção: Zack Snyder. Roteiro: Chris Terrio e David Goyer. Estados Unidos: Warner Brothers, 2016. 1 DVD (151 min).

BATMAN: A piada mortal. Direção: Sam Liu. Roteiro: Brian Azzarello. Estados Unidos: Warner Brothers, 2016. 1 DVD (77 min).

BATMAN: Assault on Arkham. Direção: Jay Oliva e Ethan Spaulding. Roteiro: Heath Corson. Estados Unidos: Warner Brothers, 2014. 1 DVD (76 min).

BATMAN: Mask of the Phantasm. Direção: Eric Radomski e Bruce Timm. Produção: Benjamin e Michael Uslan. Estados Unidos: Warner Brothers, 1993. 1 DVD (76 min).

BIMBI, B. O fim do armário: lésbicas, gays, bissexuais e trans no século XXI. Rio de Janeiro: Garamond, 2017.

CAMINHA, A. Bom crioulo. São Paulo: Hedra, 2015.

VEJA. Casal gay em desenho da Nickelodeon passou batido no Brasil. 19 jul. 2016. Disponível em: https://veja.abril.com.br/entretenimento/casal-gay-em-desenho-danickelodeon-passou-batido-no-brasil/. Acesso em: 14 jun. 2020.

CRUZ, D. P. A outra ponte do arco-íris: discursos e representações LGBTT nas histórias em quadrinhos de super-heróis norte-americanas. 2017. 226 f. Dissertação (Mestrado em Comunicação) - Universidade Federal da Paraíba, Paraíba, 2017.

UOL. Dez personagens LGBT dos desenhos animados. 10 ago. 2017. Disponível em: https://www.uol.com.br/start/listas/10-personagens-lgbt-dos-desenhos-animados.htm. Acesso em: 14 jun. 2020.

G1. Disney exibe primeiro beijo gay de desenho animado. 1 mar. 2017. Disponível em: https://g1.globo.com/pop-arte/noticia/disney-exibe-beijo-gay-pela-primeira-vez-em-desenhoanimado.ghtml. Acesso em: 14 jun. 2020.

FOUCAULT, M. História da sexualidade: o uso dos prazeres. São Paulo: Edições Graal, 2010. v. 2.

FRANCO, L.; MACHADO, L. Marvel vs. Crivella: o que diz a lei sobre ação da Prefeitura do Rio contra obra que mostra beijo gay. BBC Brasil, São Paulo, 6 set. 2019. Disponível em: https://www.bbc.com/portuguese/brasil-49614002. Acesso em: 14 jun. 2020.

GAIMAN, N. The sandman: a game of you. Nova Iorque: Vertigo, 2019. v. 5.

GIDE, A. Córidon. Rio de Janeiro: Nova Fronteira, 1985. 
GREEN, J. Além do carnaval: a homossexualidade masculina no Brasil do século XX. São Paulo: Editora UNESP, 2019.

GREEN, J.; QUINALHA, R. (org.). Ditadura e homossexualidades: repressão, resistência e a busca pela verdade. São Carlos: EDUFSCar, 2018.

JUSTICE League Dark: Apokolips War. Direção: Matt Peters e Christina Sotta. Produção James Tucker. Estados Unidos: Warner Brothers, 2020. 1 DVD (90 min).

MOORE, A. V de vingança. São Paulo: Panini livros, 2005.

MORRISON, G. Asilo Arkham: uma séria casa em um sério mundo. São Paulo: Panini livros, 2012.

MOTA, M. P. Saindo do armário: da experiência homossexual à construção da identidade gay. São Paulo: Fontenele, 2019.

NUNAN, A. Homossexualidade: do preconceito aos padrões de consumo. Rio de Janeiro: Caravansarai, 2003.

PAIVA, M. J. Elementos para uma apresentação do pensamento conservador: da disposição conservadora aos conservadorismos decorrentes. Caderno Eletrônico de Ciências Sociais, Vitória, v. 7, n. 1, p. 90-106, 2019.

PETRÔNIO. Satiricon. São Paulo: Abril, 1981.

RODRIGUES, N. O beijo no asfalto. Rio de Janeiro: Nova Fronteira, 2012.

SMEE, G. John Constantine Praticou Sexo Anal Com um Homem. Então ele é gay? Ou "só" Bissexual? Splash Pages, 17 fev. 2019. Disponível em:

https://splashpages.wordpress.com/2019/02/17/john-constantine-praticou-sexo-anal-com-umhomem-entao-ele-e-gay-ou-so-bissexual/. Acesso em: 14 jun. 2020.

TREVISAN, J. S. Devassos no paraíso: a homossexualidade no Brasil, da Colônia à Atualidade. Rio de Janeiro: Objetiva, 2018.

ŽIŽEK, S. Acontecimento: uma viagem filosófica através de um conceito. Rio de Janeiro: Zahar, 2017.

ŽIŽEK, S. Lacrimae Rerum: Ensaios sobre cinema moderno. São Paulo: Boitempo, 2018. 


\section{Como referenciar este artigo}

PAIVA, M. J. John Constantine e a questão homoafetiva: uma análise sobre representações LGBTI+ em quadrinhos de super-heróis e animações. Rev. Sem Aspas, Araraquara, v. 10, e021005, jan./dez. 2021. e-ISSN: 2358-4238. DOI: https://doi.org/10.29373/sas.v10i00.14543

Submetido em: 06/12/2020

Aprovado em: 22/02/2021

Publicado em: 30/06/2021 